\title{
Treatment of idiopathic retroperitoneal fibrosis using cyclosporin
}

\author{
A Marzano, A Trapani, N Leone, G C Actis, M Rizzetto
}

\begin{abstract}
The main goal of traditional treatment of idiopathic retroperitoneal fibrosis is limitation of morbidity, and surgery of already formed fibrous masses has been the main therapeutic approach. More recently, the knowledge that the disorder may be the result of an allergic reaction to atherosclerotic lipids has prompted the use of corticosteroids and cytotoxic drugs, which corticosteroids and cytotoxic drugs, which proved efficacious, but also toxic. On the
basis of data indicating a $T$ cell pathogenbasis of data indicating a $T$ cell pathogenesis of idiopathic retroperitoneal fibrosis, cyclosporin, a non-cytotoxic pretranscriptional inhibitor of proinflammatory cytokines, was used to treat the case reported here. A 65 year old man with aggressive here. A 65 year old man with aggressive retroperitoneal fibrosis and obstructive renal failure initially received steroids, to vertebral collapse. He responded to 5 $\mathrm{mg} / \mathrm{kg} /$ day cyclosporin, with radiological mod ther compression, and reduction in acute ther compression, and reduction in acute disease remission required stable drug concentrations. In conclusion, progress in research into the $T$ cell pathogenesis of idiopathic retroperitoneal fibrosis may justify attempts with drugs such as justify attempts with drugs such as
cyclosporin to block the disease at its origin rather than treating the morbidity.

(Ann Rheum Dis 2001;60:427-428)

Ospedale Molinette,

Torino 10126, Italy

A Marzano

A Trapani

N Leone

G C Actis
M Rizzetto

Correspondence to:

Dr Actis

actis_g@libero.it

Accepted 18 September

Surgical debulking of fibrous masses has been the traditional treatment of idiopathic retroperitoneal fibrosis (IRF), and the empirical use of steroids or, in a few cases, immune suppressors has only recently been encouraged by the evidence that IRF may be the result of an allergic reaction to lipid components of the aortic wall. ${ }^{1}$ We recently treated a patient with full

Table 1 Levels of erythrocyte sedimentation rate (ESR; normal range 0-10 mm/1st h)), $C$ reactive protein (CRP; normal range $0-5 \mathrm{mg} / \mathrm{l})$, haemoglobin (Hb; normal range $140-180 \mathrm{~g} / \mathrm{l})$, cyclosporin (CsA; trough blood range 100-240 $\mathrm{ng} / \mathrm{ml}$, according to Actis et treatment (indicated in months)

\begin{tabular}{lrrrrrrrrrr}
\hline Variable & -4 & -1 & +1 & +2 & +7 & +10 & +11 & +16 & +19 & +20 \\
\hline $\mathrm{ESR}(\mathrm{mm} / \mathrm{lst} \mathrm{h})$ & 53 & 74 & 67 & 33 & 65 & 36 & 50 & 26 & 52 & 21 \\
$\mathrm{CRP}(\mathrm{mg} / \mathrm{l})$ & 38 & 122 & 49 & 7 & 87 & 4 & 17 & 5 & 11 & 10 \\
$\mathrm{Hb}(\mathrm{g} / \mathrm{l})$ & 140 & 139 & 130 & - & - & 153 & 153 & - & 150 & - \\
$\mathrm{CsA}(\mathrm{n} / \mathrm{ml})$ & - & - & 163 & 207 & 77 & 180 & 170 & 266 & 180 & 174 \\
Creat $(\mu \mathrm{mol} / \mathrm{l})$ & 90 & 100 & 100 & 110 & 100 & 100 & 100 & 120 & 130 & 110
\end{tabular}

${ }^{\star}$ Disease activity (expressed by ESR and CRP) fluctuates around high levels four and one month before the beginning of CsA treatment. A $>50 \%$ reduction in ESR and CRP is achieved after two centration $<100$; disease activity fluctuates thereafter, but is substantially controlled at 20 monthThe mild inflammation associated anaemia disappears as the patient gains up to $2 \mathrm{~g} \mathrm{Hb}$. The creatinine concentrations tended to increase over time, reached a peak of $>33 \%$ of baseline at 19 months, but normalised spontaneously on the following determination. An initial daily prednisone
\end{abstract}

blown IRF with cyclosporin, achieving a dramatically positive result.

\section{Case report}

In July 1995, a 65 year old man was admitted because of anorexia and a $10 \mathrm{~kg}$ weight loss. His serum biochemistry included markers of inflammation (erythrocyte sedimentation rate, 80 in the hour; white blood cell count, 13670 $\mathrm{C}$ reactive protein, $94 \mathrm{mg} / \mathrm{l}$ ) and renal dysfuncCren (creatinine, $190 \mu \mathrm{mol} / 1$ ), the cause the cause of the ed tomography (CT) scan as the deposition of dense material around the lumbar aorta and the urethers, leading to hydronephrosis. On the basis of histological examination of a guided biopsy specimen showing the material to be fibrous tissue, a diagnosis was made of IRF. The posiioning of bilater stents relieved the urological (is 1995, fibrosis had worsened radiologically to involve the iliac vessels. In-hospital infusion of a maximum steroid dose, followed by a daily oral dose of prednisone of $50 \mathrm{mg}$ to be tapered off did not prevent the development of oedema in the left eg. Eventually, unchecked disease activity and ance drugs led to a state of dependence on $25 \mathrm{mg}$ steroids daily. In November 1996, the patient became bed bound because of multiple vertebral collapses. In May 1997, he was started on a daily dose of $5 \mathrm{mg} / \mathrm{kg}$ oral microemulsion cyclosporin (Novartis Pharma, Basel, Switzerland), with the aim of achieving a therapeutic concentration of $200 \mathrm{ng} / \mathrm{ml}$. A biochemical response, indicated by normalisation of the inflammatory variables, was rapid (table 1 ). In inflammatory variables, was rapid (table 1). In October 1997, the patient was weaned from
steroids, and a CT scan in December showed no progression of the retroperitoneal fibrous masses. The patient finally recovered from his lumbar fractures and had the stents removed. He is currently stable on cyclosporin without He is currently stable on cyclosporin without further need for steroids, and, at the concentrations cited above, is not showing any major cyclosporin related toxicity.

\section{Discussion}

The laboratory demonstration of sensitisation to ceroid, the clinical evidence of an association with other immune mediated connective tissue diseases, and the common finding of coincidental fibrosis at sites other than the retroperitoneum $^{1}$ all indicate an allergic pathogenesis of IRF. On this basis, steroids first, and, more anecdotally, azathioprine and cyclophosphamide, have been used as treatment, with delayed action and toxicity being limitations.

We chose to switch the patient described in this report to the non-cytotoxic drug cyclosporin, a molecule known to control the effects 
of several proinflammatory cytokines at a pretranscriptional level. ${ }^{2}$ The strategy underlying this choice was threefold. Firstly, we considered that prevention of the IRF associated morbidity largely equates to halting or delaying the progression of the inflammatory periaortic plaques towards mature fibrotic masses, and this needs a quick acting drug. Secondly, the immune cells responsible for this progression may be $\mathrm{T}$ cells, as shown by immunohistochemical studies on both IRF and the associated fibrosing diseases. ${ }^{3}$ Thirdly, the soluble effectors used by these cells may well be both inflammatory and fibrosing cytokines falling under the control of cyclosporin, a molecule with a broad sphere of action. Also, data from the literature supported this choice, showing that cyclosporin is efficacious for the treatment of other "autoimmune" diseases presumably mediated by $\mathrm{T}$ cells - for example, psoriasis, ${ }^{4}$ rheumatoid arthritis, ${ }^{5}$ and uveitis. ${ }^{6}$

There was a biochemical as well as a radiological response to this strategy. The biochemical response (fall of acute phase reactants) was early, required constant drug levels in the blood to be maintained, and tended to fluctuate with time (table 1); this was followed by the radiographic demonstration of a stable scar deposition later on. Interestingly, rapid control of the acute phase response, a relative loss of activity over time, and a late local (endoscopic) response are findings noted by us $^{7}$ and others when using cyclosporin to treat ulcerative colitis, another disease in which the role of dysregulated $\mathrm{T}$ cells is currently being emphasised. ${ }^{8}$

Thus this paper provides some theoretical grounds for the use of cyclosporin to treat IRF, together with the anecdotal evidence of its efficacy.

The success of this initial trial should not overshadow the difficulties in understanding the fine mechanisms of action of cyclosporin. A specific point that needs attention is how to reconcile a therapeutic action on IRF with the known ability of cyclosporin to enhance fibrois through the upregulation of transforming growth factor $\beta$ (TGF $\beta),{ }^{9}$ a healing cytokine. For the moment, a reasonable answer is that TGF $\beta$ is not only fibrogenic but also suppressive for several inflammatory mediators ${ }^{10}$ and its in vivo effects can only be the algebraic sum of its distinct capacities.

Further clinical trials are needed to assess whether IRF should be added to the list of the immune disturbances that benefit from the action of cyclosporin.

Kottra JJ, Reed Dunnick N. Retroperitoneal fibrosis. Radio Clin North Am 1996;34:1259-75.

2 Schreiber SL, Crabtree GR. The mechanism of action of

3 McCarthy JM, White VA, Harris G, Simons KB, Kennerdell orbit: immunohistopathic sclerosing inflammation of the roperitoneal fibrosis. Mod Pathol, 1993;6:581-7.

4 Ho VC, Griffiths CE, Albrecht G, Vanaclocha F, León titermittent short courses of cyclosporin for psoriasis unresponsive to topical therapy: a Group. Br J Dermatol 1999; 141:283-91.

5 Weinblatt ME. The role of current strategies in the future treatm therapy for, Nussenblatt RB, Whitcup SM. Cyclosporin adolescents. Ophthalmology 1998; 105:2028-34.

7 Actis GC, Aimo G, Priolo G, Moscato D, Rizzetto M, Pagn $R$. Efficacy and efficiency of oral microemulsion cyclosporin versus intravenous and soft-gelatin capsule cyclosporin in the treatment of severe steroid-refractory

E, Smith RN, Mizoguchi A Spontaneous chronic colitis in TCR alpha-mutant mice: an Immunol 2000;19:123-38.

9 Shihab S. Cyclosporin nephropathy: pathophysiology and 9 Shihab S. Cyclosporin nephropathy: pathophys
clinical impact. Semin Nephrol 1996;16:536-47

10 Rook AH, Kehrl JH, Wakefield LM, Roberts AB, Spor $\mathrm{MB}$, Burlington $\mathrm{DB}$, et al. Effects of transforming growth factor $\beta$ on the functions of natural killer cells: depresse J Immunol 1986;136:3916-20. 